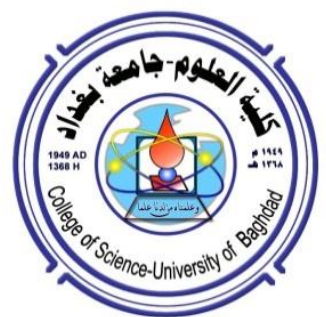

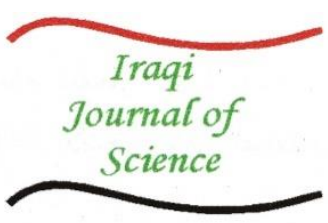

ISSN: 0067-2904

\title{
Production of a Three-Dimensional Triangulated Irregular Network (3D TIN) for Al-Karkh University of Science, Baghdad- Iraq
}

\author{
Huda M. Hamid ${ }^{1}$, Fadia W. Al-Azawi ${ }^{2 *}$ \\ ${ }^{I}$ Department of Regional Planning, College of Physical Planning, University of Kufa, Najaf, Iraq \\ ${ }^{2}$ Department of Remote Sensing, College of Remote Sensing and Geophysics, Al-Karkh University of Science, \\ Baghdad, Iraq
}

\author{
Received: 8/1/2021 Accepted: 27/7/2021
}

\begin{abstract}
Many satellite systems take cover images like QuickBird for terrain so that these images scan be used to construct 3D models likes Triangulated Irregular Network (TIN), and Digital Elevation Model (DEM). This paper presents a production of 3D TIN for Al-Karkh University of Science in Baghdad - Iraq using QuickBird image data with pixel resolution of $0.6 \mathrm{~m}$. The recent generations of high-resolution satellite imaging systems open a new era of digital mapping and earth observation. It provides not only multi-spectral and high-resolution data but also the capability for stereo mapping. The result of this study is a production of 3D satellite images of the university by merging $1 \mathrm{~m}$ DEM with satellite image for ROI using ArcGIS package Version 10.3 .
\end{abstract}

Keywords: Al- Karkh University of Science, QuickBird, DEM, TIN

$$
\begin{aligned}
& \text { أنتاج شبكة ثلاثية الأبعاد مثلثية غير منتظمة لجامعة الكرخ للعلوم } \\
& \text { هاى تحمل حميد1، فاديه وضاح العزاوي2" }
\end{aligned}
$$

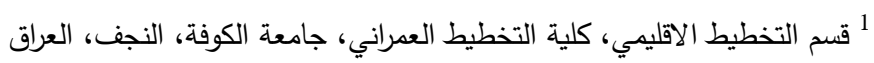

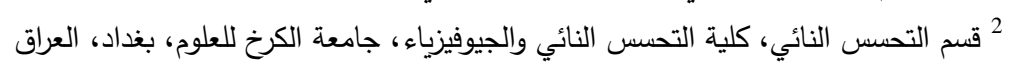

تلتقط العديد من أنظمة الأقمار الاصطناعية مثل QuickBird of the terrain صور غلاف بحيث يتم

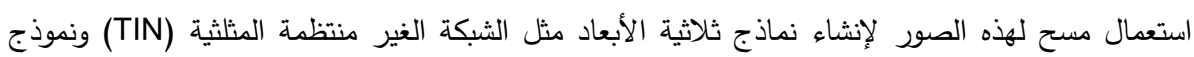

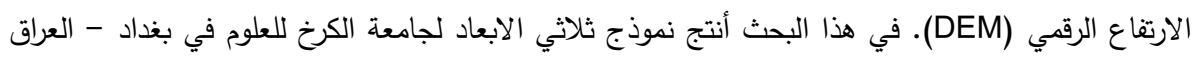

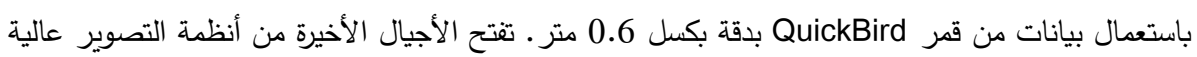

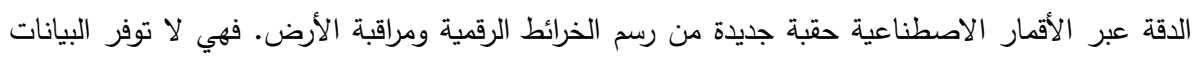

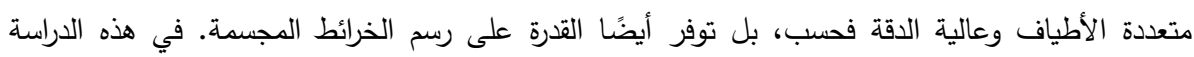

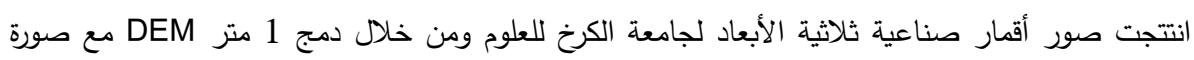

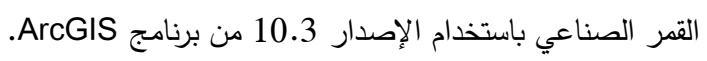

\section{Introduction}

Satellite images in the range of (0.6-2.4) m resolution were collected by QuickBird Satellite [1]. It is an excellent source of environmental data. It is useful for detecting changes in forest,

*Email: Fadia.alazawi@kus.edu.iq 
land use, agriculture, and climate. QuickBird imagery is able to identify the adequacy of soil erosion quickly and irrigation. It is also possible to closely monitor and even optimize the use of fertilizer, pesticides, and other agricultural treatments using QuickBird data.

Environmental impacts of logging, such as road construction, stream sedimentation associated with clear-cut harvesting, and slash-and-burn activities, can be clearly detected from the imagery. In addition, QuickBird satellite data can be potentially useful in hazard and environmental assessments [2].

It can be used to assess planning of risks-emergency response, flooding, and evacuation. It is also possible to map habitats and assess wetlands, prospect minerals and potential mining sites using these images $[2,3]$.

A scene can represent a height estimation of a known geographic range. The coming about 3D lattice (compared to latitude, longitude, and height) separately can be utilized to produce a 3D representation of the scene [4].

Georeferenced, the data which is remotely sensed can then be overlain on the DEM to produce accurate visualizations of spatial relationships in the data, as well as measurement and calculation of hydrologic and geomorphic parameters related aspect, and slope [4].

A Triangulated Irregular Network (TIN) is a data structure for representing 3D surfaces comprised of connected, and not overlapped triangles. This is one of the techniques used in the GIS field to represent terrain models [5].

The amount of details in a TIN is a direct function of the number of sample points used in original data source. Hence, more points used to create the TIN, will result more detailed in the image. Furthermore, using more points, means longer processing time required to build TIN. A TIN surface was created from features that contain elevation information. To build TIN surface and by using ArcGIS, under the analysis tab, choose tools button. Geoprocessing pane will appear. Choose Create TIN and set the parameters then click run.

TINs are the most useful technique for representing a continuous surface of a vector in GIS system. Vector data provide a way to represent real world features within the GIS environment. Data sets comprising any combination of brake lines, contours, and point elevations can be combined as input to create a TIN [6].

TIN can be used to approximate a terrain surface to a required accuracy with fewer polygons than a DEM. This is because the sample resolution can be varied across the terrain. TINs are especially useful for analytical purposes because it is a good technique for representing surfaces, aspect easily derived, and simplify calculations of surface area and volume. Further benefits of TINs include the range of geographic features they can model, including topographical summits, saddle points, valleys, pits, and cols; linear features such as streams, ridges; and features that require multiple $\mathrm{z}$-coordinates for the same $(\mathrm{x}, \mathrm{y})$ coordinate. A TIN can also be sculpted to accommodate man-made features of the terrain, such as buildings and roads [7].

\section{Materials and Methods}

In this study, a TIN surface was created from features, such as points, lines, and polygons, that contain elevation information. These features used as spot locations of elevation data, and polygons were used to clip the TIN to a Region Of Interest (ROI). AlKarkh University of Science lies in Haifa Street, Baghdad, Iraq. Its coordinates are 33.341913 and 44.374226, as Latitude and Longitude, respectively. This area was selected as ROI in this research [8].

Also, raster surface was converted to a TIN to add additional features, such as roads, and streams to surface model.

The procedure of production of 3D satellite images is shown in the following flowchart; Figure 1. 


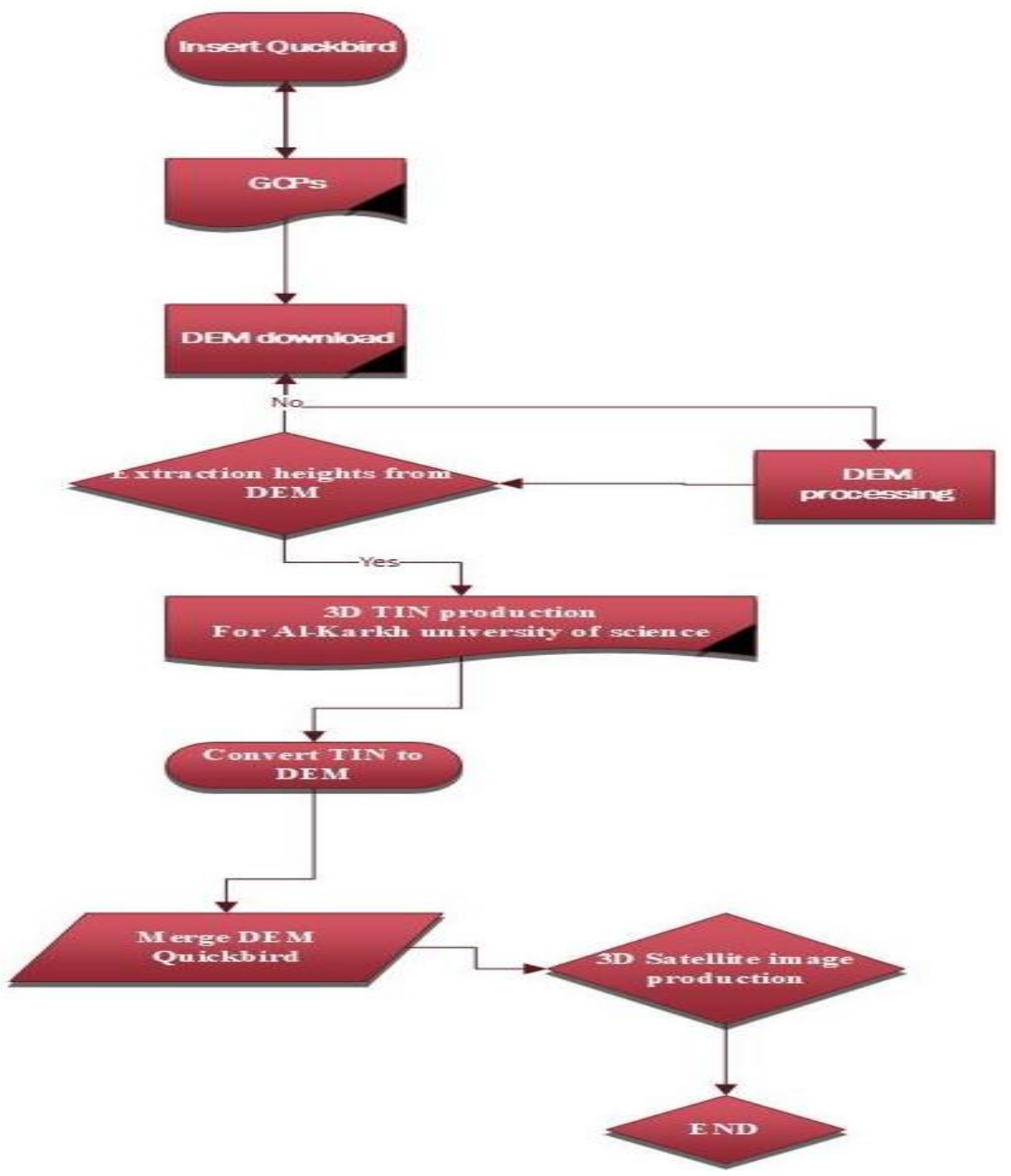

Figure 1-Steps for our work

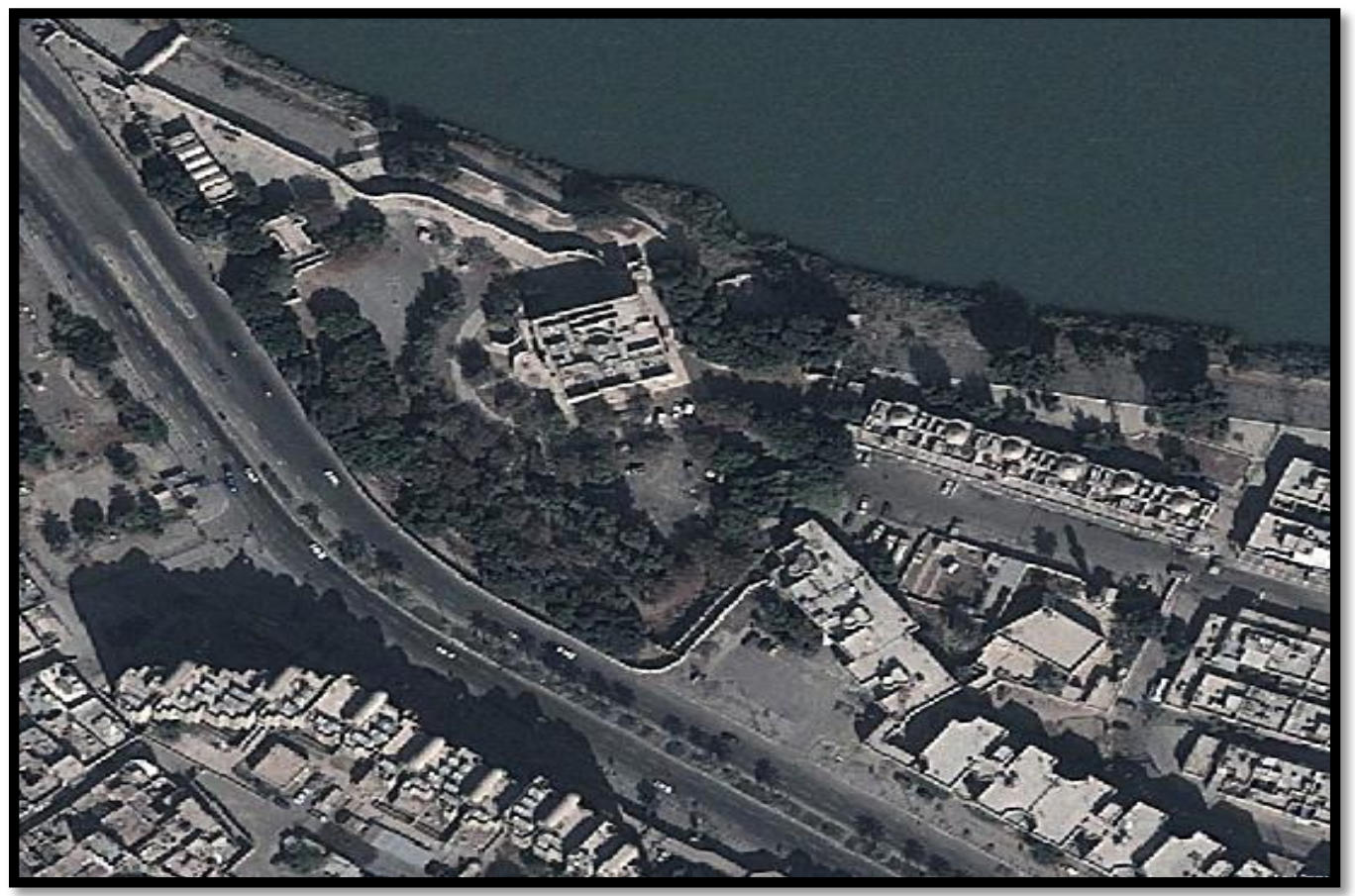

Figure 2 A map depicting the study area in Haifa, which is located in the capital of Iraq, Baghdad. 
Insert Quickbird a fine resolution (0.6) m remotely sensed image, Figure 2 East and north points (33.341913 and 44.374226) were filled on the Region Of Interest (ROI) then these points were corrected according to ground control point using Differential Global Positioning System (DGPS) Topcon type at Baghdad University as shown in Figure (3 \& 4).

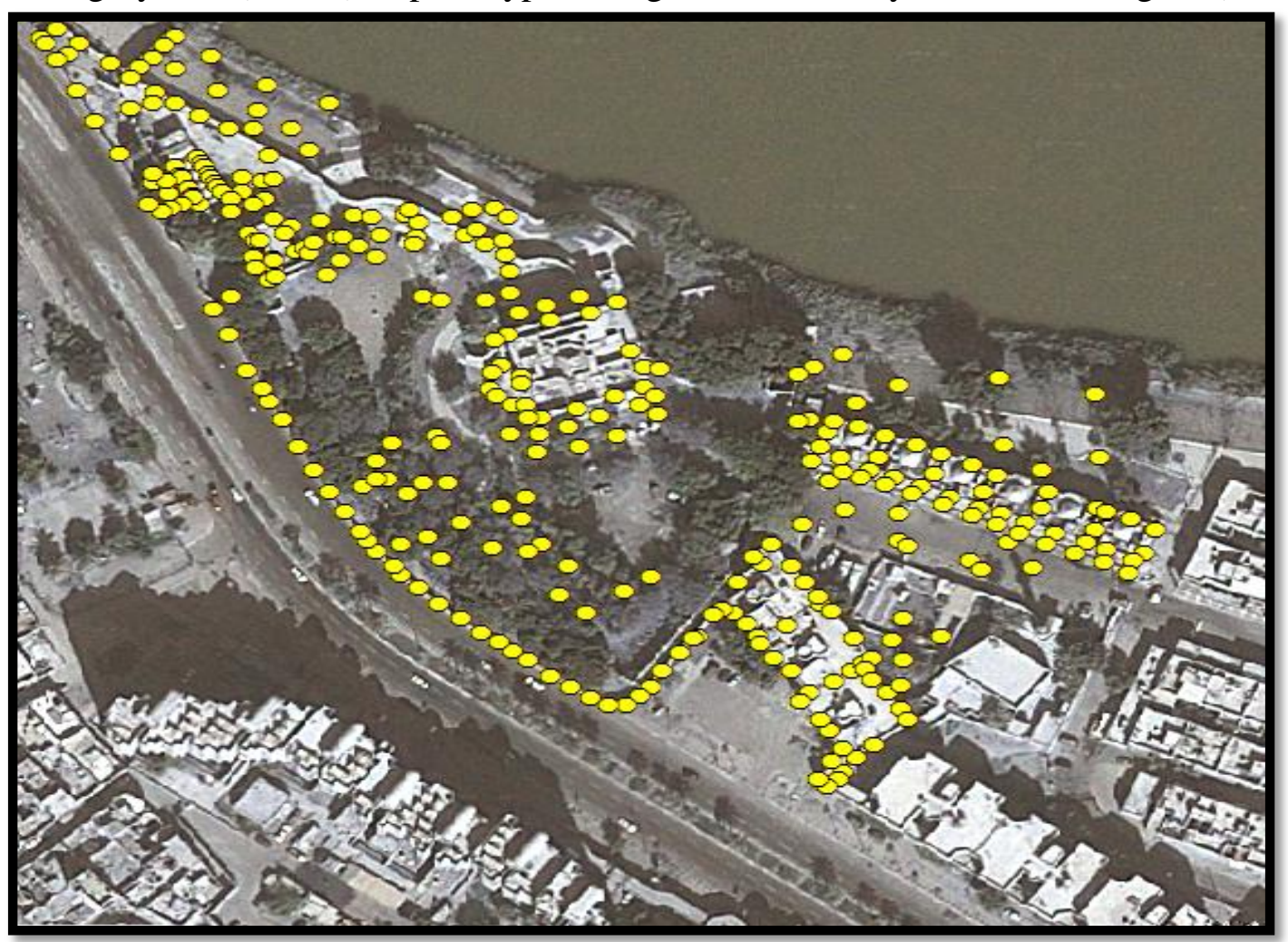

Figure 3-GCPs for the ROI

Digital Elevation Mode image with resolution of $30 \mathrm{~m}$ was downloaded from the website https://earthexplorer.usgs.gov/ by the following steps:

- Open the GLOVIS page.

- From the collection menu, types of desired data were selected.

- The period time of sweeping was determined, then the image was download by choose add.

- The images were treated after that the elevations were extracted from it.

In this study, the ground control points were selected using the University of Bagdad site in Jadriya as a referenced source. 


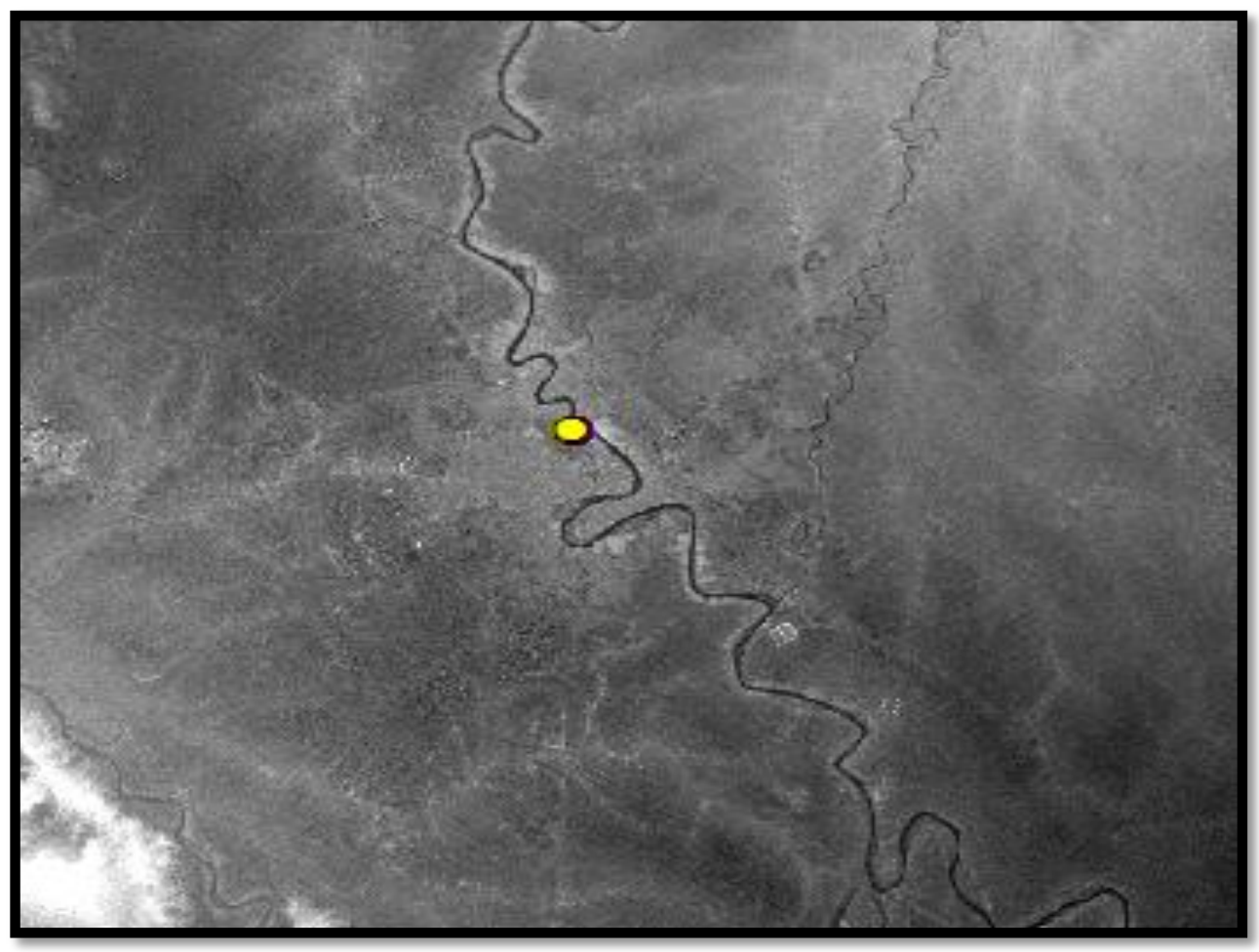

Figure 4-One of the GCPs in the ROI.

TIN with resolution of $1 \mathrm{~m}$ was produced using ArcGIS Spatial Analyst and Spatial Interpolation tools as shown in Figure $(5 \& 6)$.

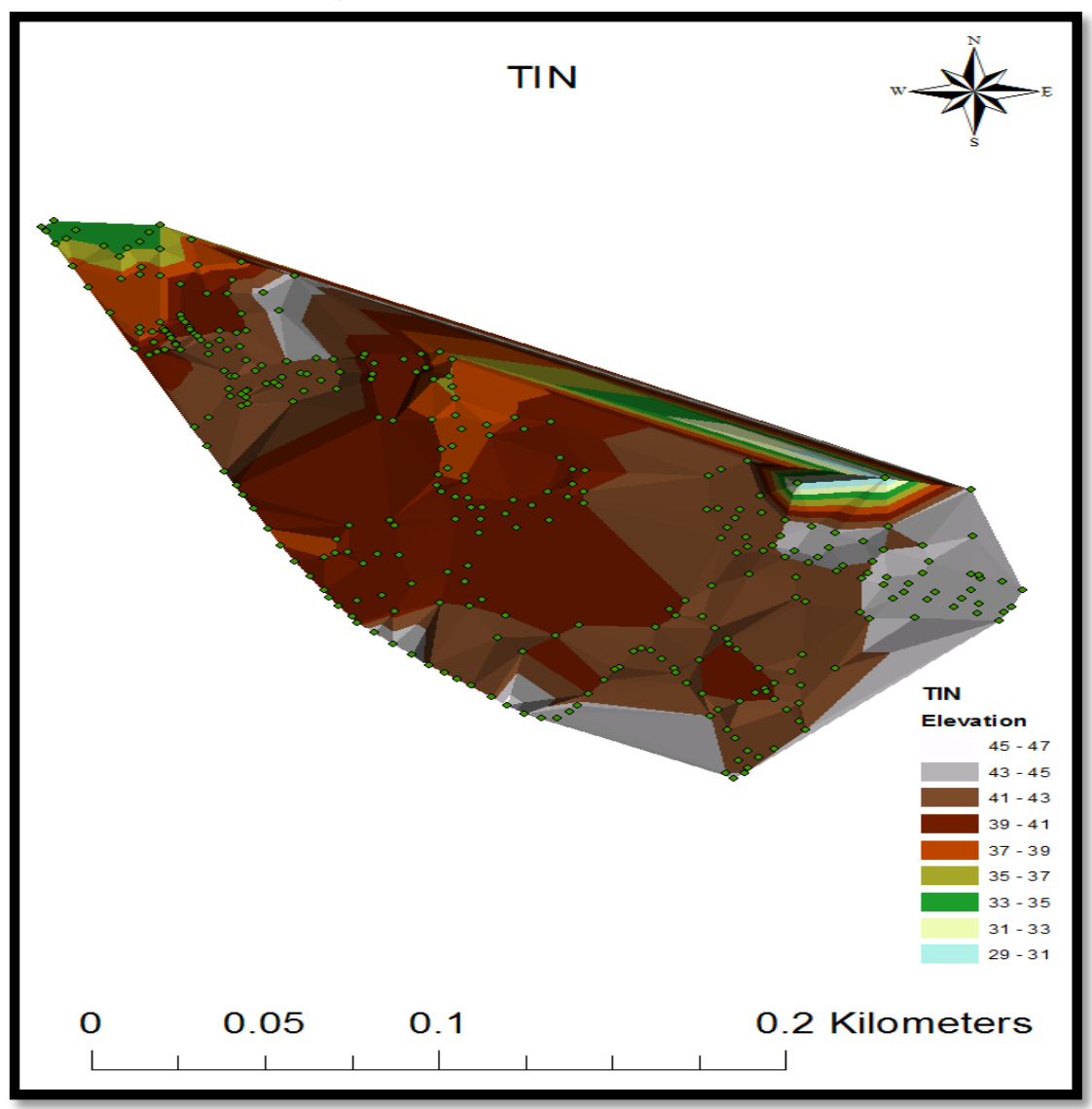

Figure 5-TIN with resolution of $1 \mathrm{~m}$ was produced using ArcGIS Spatial Analyst and Spatial Interpolation tools. 


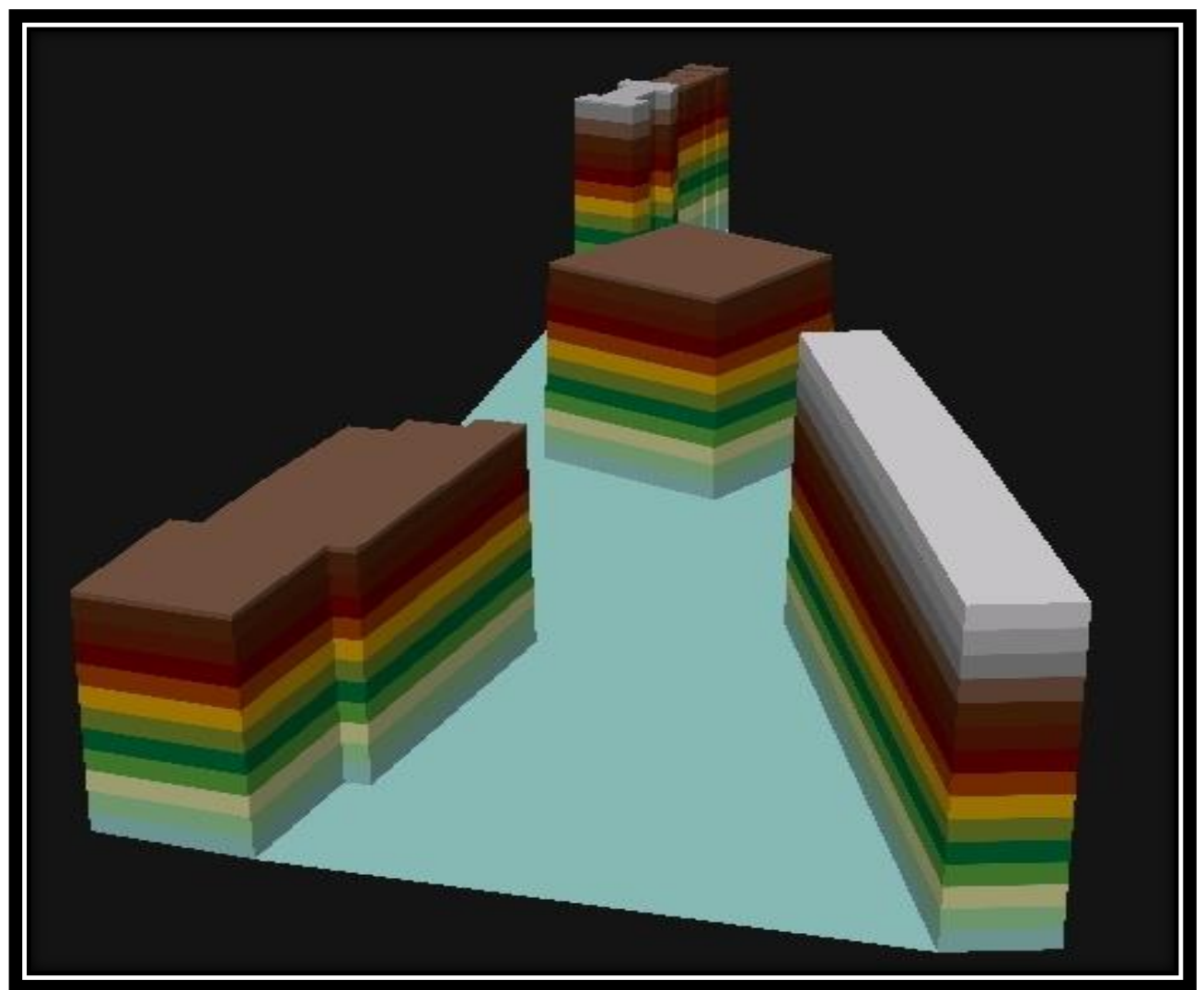

(a)

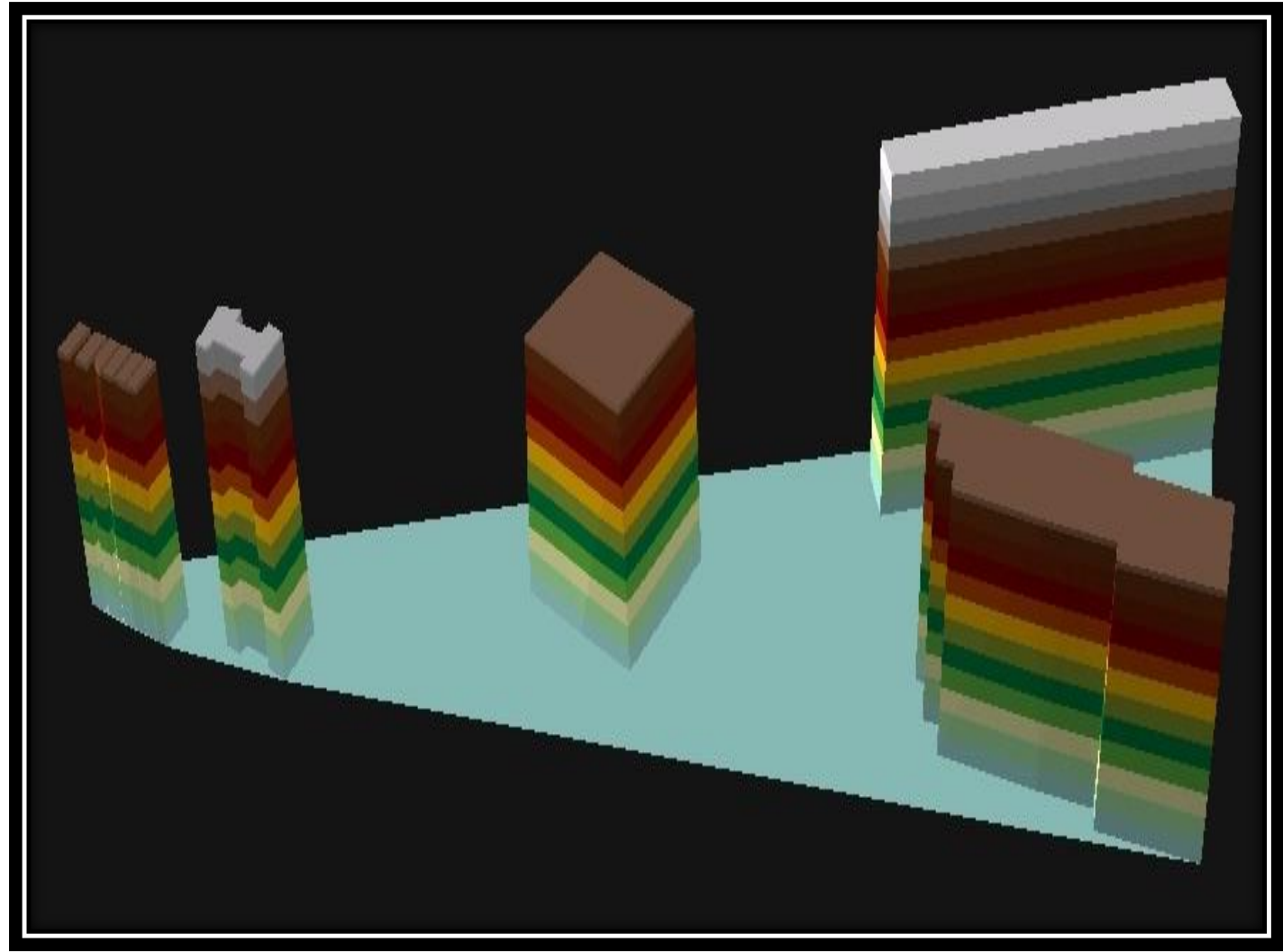

(b)

Figure 6-(a and b) 3D TIN was producing for Al-Karkh University of Science. 
$1 \mathrm{~m}$ DEM was merged with satellite image of the study region using ArcScene to product 3D satellite image for Al-Karkh University of Science as shown in Figure 7.

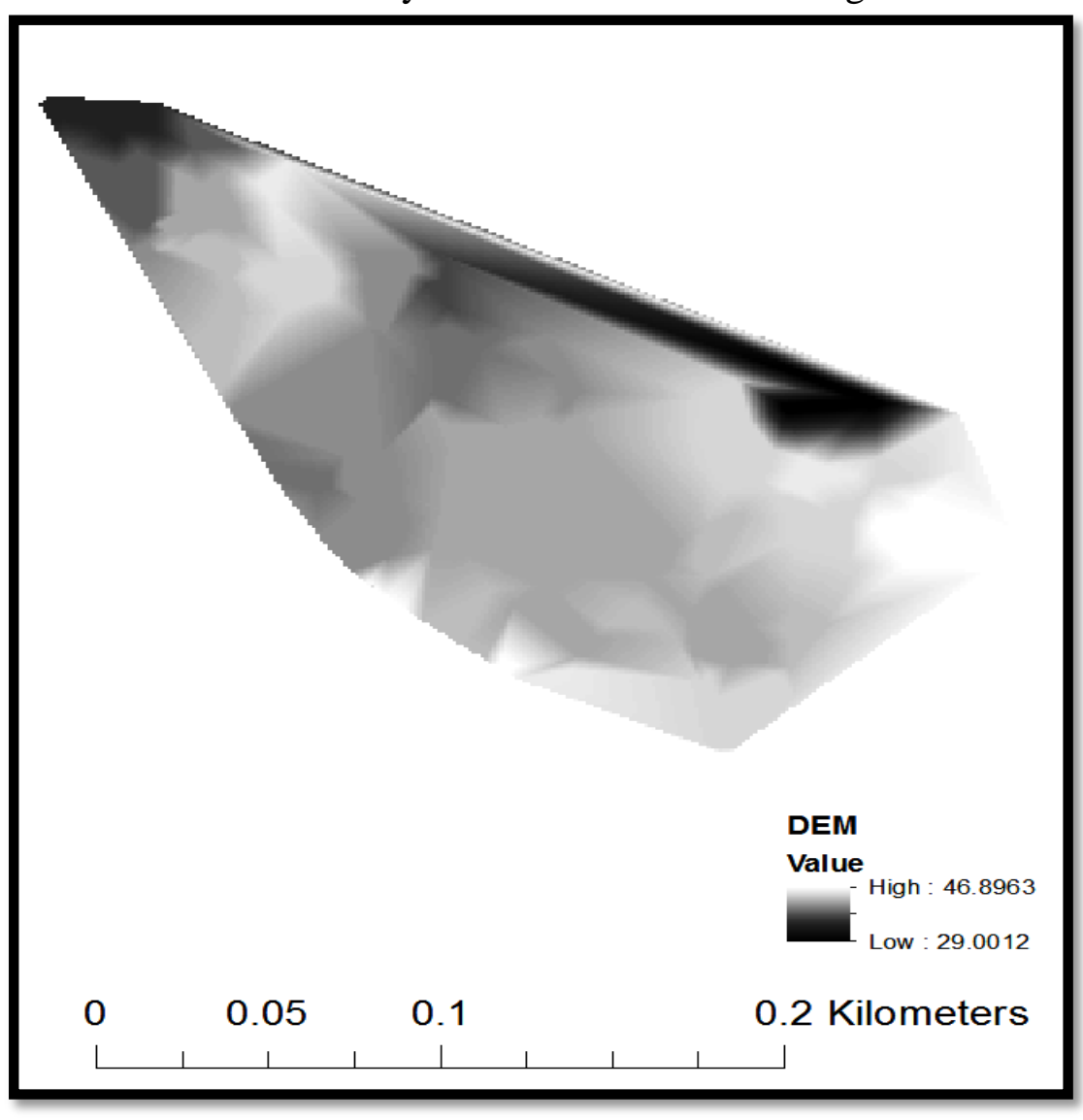

Figure 7-TIN converted to DEM with resolution of $1 \mathrm{~m}$ through ArcMap version 10.3.

\section{Results \& Discussion}

The outcome of this work was creation of a 3D TIN for Al-Karkh University of Science in Baghdad, Iraq for the first time using QuickBird image data of $0.6 \mathrm{~m}$ pixel resolution. A favor of using a TIN over a rasterized compared with DEM (in mapping and analysis) is that the points of a TIN are variably distributed based on an algorithm that estimates the points which are the most important to create an accurate and exact representation of the terrain. In TIN, the data input is therefore flexible, supple, and fewer points were needed to be stored compared to a raster DEM with regularly and orderly distributed points.

\section{Conclusions}

The main conclusion points can be summarized as follows:

1. The creation of the high resolution DEM $(1 \mathrm{~m})$ was done using the TIN method. From the obtained results, the highest elevation is $46.8963 \mathrm{~m}$ and the lower elevation is $29.0012 \mathrm{~m}$ for the case study.

2. The 3-D high resolution satellite imagery were created for AL-Karkh University of Science by application of high-resolution TIN. This region is useful for different spatial applications for our university. 


\section{References}

[1] Parcak S.H. Routledge. "Satellite Remote Sensing For Archaeology". Taylor and Francis Group London \& New York, 2009.

[2] GAO, J. "Digital Analysis of Remotely Sensed Imagery”. McGraw-Hill Companies, Inc, 2009.

[3] Jing, L. and Stephansson, O. "Fundamentals of Discrete Element Methods for Rock Engineering: Theory and Applications", vol 85. $1^{\text {st }}$ edition. Elsevier Science, 2007.

[4] Li, Z., Zhu, Q., and Gold, C. "Digital Terrain Modeling Principles and Methodology", CRC PRESS, 2005.

[5] Kresse, Wolfgang, Danko, David M. "Springer Handbook of Geographic Information", 2nd Edition, Abridged. Merkle, Dieter, 2012.

[6] K.T. Tang. "Mathematical Methods 1123 for Engineers and Scientists", Springer-Verlag Berlin Heidelberg, 2007.

[7] Huda M. Hamid, Fadia W. Al-Azawi, Zainab D. Abbas, Sarah T. Hassan and Zaid F. Makki. "Producing A Geographical Information System (GIS) Model for The Preliminary Location of Groundwater Wells for The Regions Of Al Najaf Government", Plant Archives. vol.19. no.2, pp. 3515-3521, 2019.

[8] Jan Muhammad, Fadia W. Al-Azawi*, Saad Malik , Ali Imran, Abdul Hadi Bhutto. "An Assessment of the Temperature Change Scenarios Using RS \& GIS Techniques-A Case study of Sindh", Iraqi Journal of Science, Vol. 57, No.4C, pp: 2979-2993, 2016. 